\title{
Pneumatosis intestinalis and hepatic-portal-mesenteric venous gas in intestinal ischemia
}

\author{
L. Chien-Hua, Y. Jyh-Cherng, H. Huan-Fa', W. Hurng-Sheng'2, C. Shih-Yi and C. Chu-Hsin \\ Division of General Surgery. Department of Surgery. Tri-Service General Hospital. National Defense Medical Center. \\ Taipei. Taiwan. ${ }^{1}$ Department of Surgery. Yee-Zen General Hospital. Taoyuan, Taiwan. ${ }^{2}$ Department of Surgery. Show \\ Chwan Memorial Hospital. Changhua, Taiwan
}

\begin{abstract}
Objective: the purpose of this study was to report the authors' experience in the diagnosis, management, and clinical outcome of intestinal ischemia with pneumatosis intestinalis (PI) and hepatic-portal-mesenteric venous gas (HPMVG).

Experimental design: a retrospective analysis.

Method: the medical records of 12 cases of intestinal ischemia with PI and HPMVG spanning the last 10 years were reviewed. Clinical characteristics, imaging study results, surgical findings, histological findings, management, and clinical outcome were evaluated.

Results: of the 12 cases that were evaluated, 9 patients presented with abdominal distension, three, with abdominal pain, five, with shock on admission, and six, with fever. Most patients (83\%) had a history of diabetes mellitus. Dilated loops of bowel were identified on plain film radiography in 9 of 12 of patients. Only 3 cases were initially suspected of having abnormal gas over the RUQ or intramural intestine. All patients underwent abdominal computed tomography (CT). Nine patients were diagnosed with ischemic changes of the intestine ( 2 cases had colon involvement), and 3 patients were found to have a gangrenous intestine. While all patients underwent segmental resection of the intestine, ten of 12 patients died post-operatively.

Conclusions: abdominal CT findings of PI and HPMVG in intestinal ischemia do not appear to either directly correlate with the gross findings or predict clinical outcome. The clinical outcome of patients affected with this condition was poor, even following surgical intervention. A positive clinical outcome may depend on the severity and extent of the underlying disease(s).
\end{abstract}

Key words: Pneumatosis intestinalis. Hepatic-portal-mesenteric venous gas. Intestinal ischemia.

Chien-Hua L, Jyh-Cherng Y, Huan-Fa H, Hurng-Sheng W, Shih-Yi C, Chu-Hsin C. Pneumatosis intestinalis and hepaticportal-mesenteric venous gas in intestinal ischemia. Rev Esp Enferm Dig 2007; 99: 96-99.

Received: 16-10-06.

Accepted: 13-11-06.

Correspondence: Chu-Hsin Chuang. Division of General Surgery. Tri-Service General. Hospital, 325, Cheng-Kung Road, Sec 2. Neihu 114. Taipei, Taiwan, R.O.C.e-mail: linjh93@yahoo.com.tw

\section{INTRODUCTION}

Pneumatosis intestinalis (PI) is a rare condition characterized by subserosal and submucosal gas-filled cysts in the gastrointestinal tract. PI has two forms: primary or idiopathic, and secondary PI. Primary PI, or pneumatosis cystoides intestinalis (observed in $15-20 \%$ of all PI cases) is a benign condition that is often asymptomatic. This type of PI is characterized by multiple thin-walled cysts found in the submucosa or subserosa of the colon. If the cysts protrude into the lumen of the colon they may mimic polyps or carcinomas. Primary PI typically resolves spontaneously. In contrast, secondary PI, observed in the remaining $85 \%$ of cases, more commonly involves the small bowel or ascending colon (1-3). Secondary PI may be associated with bowel ischemia and perforation (4), and is diagnosed by computed tomography (CT) once gas appears in the hepatic-portal-mesenteric vein (HPMVG). Unlike primary PI, this latter type of PI is associated with a high mortality rate. The etiology, clinical findings, imaging findings, and clinical outcomes of 12 cases diagnosed with PI and HPVG were retrospectively analyzed and are discussed herein.

\section{METHODS}

From May 1996 to May 2006, 12 consecutive cases of adult patients ( 8 men and 4 women; mean age, 61.75 years; range, 45 to 86 years) who had intestinal ischemia with computer tomography (CT) findings of PI or HPMVG were reviewed. Primary PI and secondary PI not attributable to ischemic intestine were excluded. Their clinical characteristics, including age, gender, clinical presentation, underlying diseases, and abdominal plain film radiography, sonography, and computed tomography results were all recorded. Operative and histological findings were also noted in addition to salient features of case management and clinical outcome. 


\section{Image identification}

"Gas within the liver" needs to be differentiated from HPMVG and pneumobilia. HPMVG is typically located in the peripheral region (Fig. 1), and the gas of pneumobilia is located more centrally (Fig. 3). Another method for differentiation is to check whether the gas is in the common bile duct or portal vein.

\section{RESULTS}

Twelve patients over 10 years were identified in this retrospective study. Eight patients were males and the remaining 4 were females.

\section{Clinical presentation}

As indicated in table I, mean patient age was 61.75 years (range: 45 to 86 years). Nine patients presented with abdominal distension, 3 patients with abdominal pain, 5 patients presented with shock, and 6 patients presented with fever. Ten patients had a history of diabetes mellitus (DM). Other comorbidities included hypertension $(\mathrm{n}=$ $5)$, arrhythmia $(n=6)$, coronary artery disease $(C A D)(n$ $=4)$, congestive heart failure $(\mathrm{CHF})(\mathrm{n}=3)$, and uremia requiring regular hemodialysis $(\mathrm{n}=2)$. Two patients had

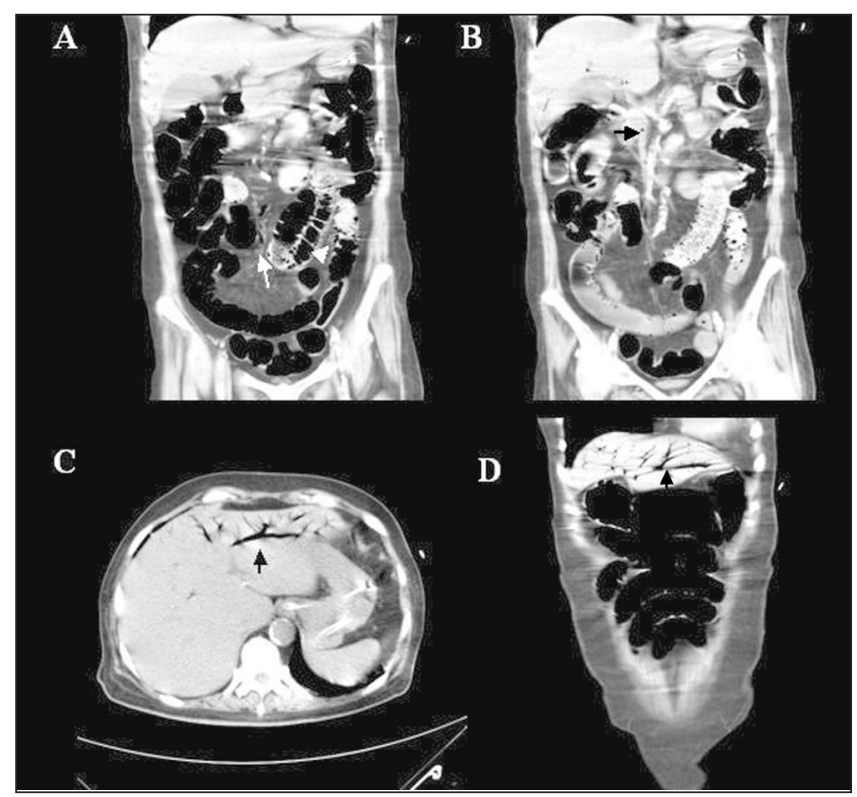

Fig. 1. A 59-year-old female patient with type II diabetes and nephropathy who underwent regular hemodialysis for 5 years presented with abdominal pain of one week's duration. Contrast enhanced computed tomography of the abdomen demostrated cystic pockets of gas in submucosa or subserosa of the bowel wall (Panel A, white arrow head) and mesentery (Panel A, white arrow; gas bubbles in the superior mesentery vein (Panel $B$, arrow); and gas within the veins that appeared as linear gas densities in the periphery of the liver (Panel C and D arrow).

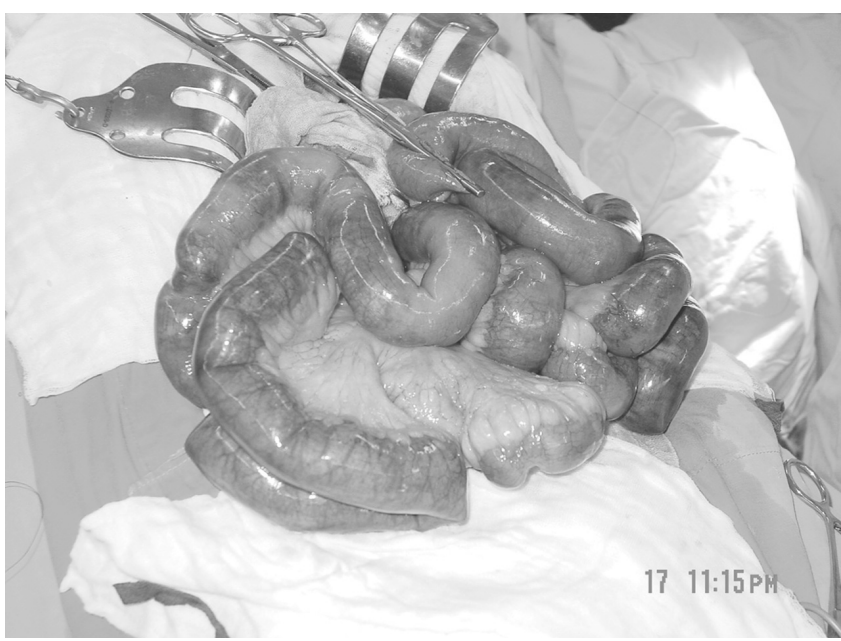

Fig. 2. The (previously described) patient underwent urgent laparotomy which revealed skip ischemia changes of the jejunum and ileum.

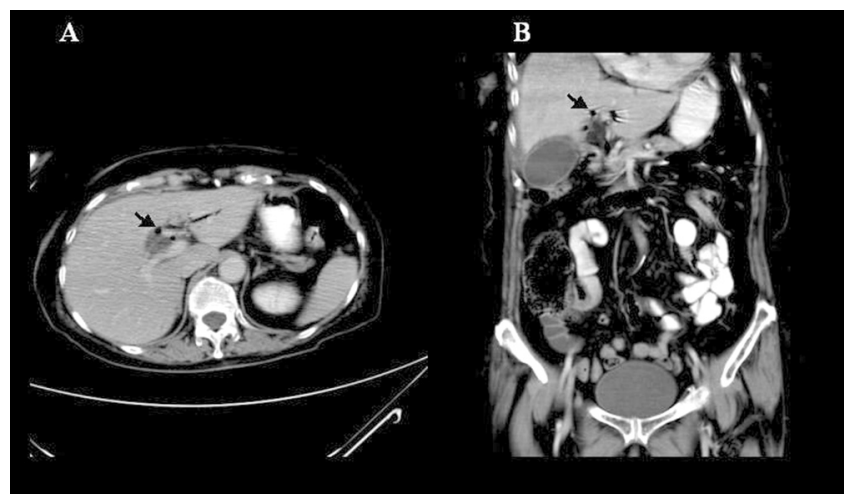

Fig. 3. Abdominal computed tomography demostrating pneumobilia which appeared as linear pockets of gas located more centrally ( $A$ and B, black arrow).

a history of stroke, and 2 further patients had previously had a limb amputated.

\section{Imaging findings (Table II)}

Plain film radiographs (KUB) of all 12 patients were reviewed. Nine patients had dilated bowel loops. One patient's report identified a region over the RUQ of the abdomen that was suspicious of linear gas, one patient had both dilated loops and intramural intestinal gas, and one patient had gas over the RUQ of the abdomen as well as intramural intestinal gas.

A sonography of the abdomen was performed for only 2 of the 12 patients. Of these, 1 patient had fluid collected in the pelvis, and one patient reportedly suffered from ileus.

All 12 patients underwent abdominal CT, including 2 patients reported as isolated PI, 2 patients reported as isolated HPMVG, and the other 8 patients reported as PI and HPMVG. 
Table I. Summary of clinical characteristic in 12 patients with intestinal ischemia with PI or hepatic-portal-mesenteric venous gas

\begin{tabular}{|c|c|c|c|c|}
\hline Case & Age & Sex & Presentation & Underlying disease \\
\hline 1 & 59 & M & Abdominal distension and pain, shock & HTN, DM, arrhythmia, CAD, AK amputation, CHF, DM \\
\hline 2 & 47 & $\mathrm{~F}$ & Abdominal distension, fever, shock & DM \\
\hline 3 & 86 & $\mathrm{~F}$ & Abdominal distension, vomiting, shock & DM, uremia, arrhythmia, CAD, stroke, \\
\hline 4 & 69 & M & Abdominal distension, Fever & DM \\
\hline 5 & 66 & M & Fever & DM, HTN, CHF, arrhythmia \\
\hline 6 & 72 & M & Abdominal distension, fever, shock & DM, HTN \\
\hline 7 & 70 & $\mathrm{~F}$ & Abdominal distension & Arrhythmia, CAD \\
\hline 8 & 61 & M & Abdominal distension and pain, vomiting, fever, shock & HTN \\
\hline 9 & 55 & M & General weakness, peritonitis & DM, stroke, arrhythmia \\
\hline 10 & 54 & M & Abdominal pain, tarry stool & DM, arrhythmia, CHF \\
\hline 11 & 57 & M & Abdominal distension, fever & DM, HTN, CAD, uremia, toe amputation, sacral pressure sore \\
\hline 12 & 45 & $\mathrm{~F}$ & Abdominal distension, vomiting & DM \\
\hline
\end{tabular}

HTN: hypertension; DM: diabetes mellitus; CAD: coronary artery disease, AK: above knee, CHF: congestive heart failure.

Table II. Summary of imaging findings, histological findings, treatments and outcomes in 12 patients of intestinal ischemia with PI or hepatic-portal-mesenteric venous gas

\begin{tabular}{|c|c|c|c|c|c|c|c|}
\hline Case & X-ray & Sonography & CT & Operative finding & Treatment & Histology & Outcome \\
\hline 1 & $\mathrm{DBL}+\mathrm{RUQ}$ air & $\begin{array}{l}\text { Fluid collection } \\
\text { in pelvis }\end{array}$ & $\mathrm{PI}+\mathrm{HPMVG}$ & $\begin{array}{c}\text { Ischemia change, no } \\
\text { necrosis, jejunum and ileum }\end{array}$ & SR of intestine & $\begin{array}{l}\text { Gas bubbles in submucosa } \\
\text { mesenteric thrombosis }\end{array}$ & Expired \\
\hline 2 & DBL & - & $\mathrm{Pl}$ & Gangrene of ileum (120 cm) & SR of intestine & Necrosis, mesenteric thrombosis & Alive \\
\hline 3 & $\begin{array}{l}\mathrm{DBL}+\text { intramural } \\
\text { intestinal }\end{array}$ & - & $\mathrm{PI}+\mathrm{HPMVG}$ & $\begin{array}{l}\text { Ischemia change, no necrosis } \\
\text { jejunum and ileum }\end{array}$ & $\begin{array}{l}\text { SR of intestine + } \\
\text { ileostomy }\end{array}$ & $\begin{array}{c}\text { Gas bubbles in submucosa, mesenteric } \\
\text { thrombosis, hemorrahge }\end{array}$ & Expired \\
\hline 4 & DBL & - & $\mathrm{Pl}$ & $\begin{array}{l}\text { Isechemia change of jejunum } \\
\qquad(50 \mathrm{~cm})\end{array}$ & SR of intestine & Gas bubbles in submucosa & Alive \\
\hline 5 & DBL & - & $P I+H P M V G$ & Gangrene of ileum $(100 \mathrm{~cm})$ & SR of intestine & Necrosis, gas in submucosa & Expired \\
\hline 6 & DBL & - & $P I+H P M V G$ & $\begin{array}{l}\text { Ischemia change, jejunum and } \\
\text { ileum }(200 \mathrm{~cm})\end{array}$ & SR of intestine & Gas bubbles in submucosa & Expired \\
\hline 7 & DBL & - & $\mathrm{PI}+\mathrm{HPMVG}$ & $\begin{array}{l}\text { Ischemia change of jejunum } \\
\text { and ileum }\end{array}$ & SR of intestine & Gas bubbles in submucosa & Expired \\
\hline 8 & DBL & Heus & $\mathrm{PI}+\mathrm{HPMVG}$ & $\begin{array}{l}\text { Gangrene of jejunum and } \\
\text { ileum }(70 \mathrm{~cm})\end{array}$ & SR of intestine & Necrosis, mesenteric thrombosis & Expired \\
\hline 9 & DBL & - & HPMVG & $\begin{array}{l}\text { Ischemia change of ileum to } \\
\text { cecum }\end{array}$ & SR of intestine & Gas bubbles in submucosa & Expired \\
\hline 10 & $\mathrm{DBL}$ & - & $\mathrm{PI}+\mathrm{HPMVG}$ & Ischemia change, terminal ileum & SR of intestine & Gas bubbles in submucosa & Expired \\
\hline 11 & $\begin{array}{c}\mathrm{DBL}+\mathrm{RUQ} \\
\text { gas + intramural } \\
\text { intestinal gas DBL }\end{array}$ & - & $\mathrm{PI}+\mathrm{HPMVG}$ & $\begin{array}{l}\text { Ischemia change of jejunum, } \\
\text { ileum to transverse colon }\end{array}$ & SR of intestine & $\begin{array}{l}\text { Gas bubbles in submucosa } \\
\text { skip necrosis }\end{array}$ & Expired \\
\hline 12 & DBL & - & HPMVG & Ischemia change, ileum & SR of intestine & $\begin{array}{l}\text { Gas bubbles in submucosa, } \\
\text { no necrosis }\end{array}$ & Expired \\
\hline
\end{tabular}

\section{Operative findings, histological findings, treatment, and outcome (Table II)}

The intraoperative macroscopic evaluation revealed 9 patients with ischemic changes in their intestine: two cases involved the colon and 3 patients were diagnosed with bowel gangrene. Histopathology revealed that the 3 patients with macroscopic evidence of intestinal gangrena eventually had bowel necrosis. One case (No. 11) appeared to have macroscopic evidence of ischemia at the time of surgery, but histology later revealed necrosis. Ten patients were identified with gas bubbles in the submucosa, and 4 patients with mesenteric thrombosis were detected.

All patients underwent segmentary intestinal resection, and one patient also underwent ileostomy. Ten of the 12 patients died during the post-operative period.

\section{DISCUSSION}

PI and HPMVG are associated with transmural bowel infarction possibly due to bowel ischemia, ulcerative colitis, diverticulitis, intraabdominal abscess, small-bowel obstruction, neoplastic bowel-wall damage, trauma, or gastric ulcer (5-7). Two mechanisms have been proposed to describe the pathogenesis of this condition: bowel distension or ulceration permits gas to enter the bowel wall and hepatic-portal-mesenteric venous system; or gas-for- 
ming anaerobic bacteria may invade the bowel wall $(5,6,8)$.

Given the high mortality rate associated with this condition, particularly with secondary PI (5-8), it was the goal of this study to report our experience regarding PI or HPMVG in patients with intestinal ischemia. Most of the patients described in this retrospective study presented with abdominal distension (75\%), fever (50\%), and shock (42\%). DM (84\%), cardiovascular disease including hypertension (42\%), arrhythmia (50\%), and CAD $(33,3 \%)$ were the most commonly encountered comorbidities. It is possible that DM and cardiovascular disease were the primary contributing factors that led to intestinal ischemia.

We propose that following the development of ischemic changes within the intestine an ileus resulted, and intestinal obstruction ensued. The intestinal mucosal damage and obstruction permitted gas to enter the bowel wall, whereby the gas then progressed to the mesentery and portal veins.

Regarding imaging studies, abdominal CT appears to be more sensitive than either plain film radiography or sonography for the detection of intestinal ischemia with PI or HPMVG. CT findings in PI were almost always compatible with histological findings; however, the severity of intestinal gross ischemia changes was not compatible with CT findings in this study. As illustrated in figures 1 and 2, PI and HPMVG were identified on CT, but gross intraoperative findings indicated ischemia, not gangrene. It is possible that while CT may identify PI, the intestine may appear grossly ischemic, not gangrenous.

While several reports indicate that immediate laparotomy is necessary for patients presenting with HPMVG $(9,10)$ our results are admittedly disappointing. In this study surgery did not appear to ameliorate the clinical outcome. Surviving patients rarely had underlying diseases, and showed a minimal amount of intestinal ischemia or gangrene when compared to patients who died postoperatively. The mortality rate may be associated with disease severity, but a more exhaustive analysis with a large sample size is required to draw solid conclusions or recommendations.

In conclusion, abdominal $\mathrm{CT}$ appears to be a sensitive method for detecting PI or HPMVG in intestinal ischemia, but it is not completely consistent with clinical presentation, macroscopic intraoperative findings, or clinical outcome. Clinical outcome appears to be highly associated with the severity of intestinal ischemia and the extent of the patient's underlying disease(s).

\section{REFERENCES}

1. Sleisenger \& Fordtran's. Gastrointestinal and liver disease. $7^{\text {th }}$ ed. 2006. p. 2821-3.

2. Margulis A, Burhenne H. Alimentary tract radiology. $4^{\text {th }}$ ed. 1989. p. 296-8.

3. Eisenberg R. Gastrointestinal radiology. $2^{\text {nd }}$ ed. 1989. p. 881-91.

4. Tchabo NE, Grobmyer SR, Jamagin WR, Chi DS. Conservative management of pneumatosis intestinalis. Gynecol Oncol 2005; 99: 782-4.

5. Grifiths DM, Gough MH. Gas in the hepatic portal veins. Br J Surg 1986; 73: 172-6.

6. Wiesner W, Mortele KJ, Glickman JN, Ji H, Ros PR. Pneumatosis intestinalis and portomesenteric venous gas in intestinal ischemia: Correlation of CT findings with severity of ischemia and clinical outcome. AJR 2001; 177 (6): 1319-23.

7. Kinoshita H, Shinozaki M, Tanimura H, Umemoto Y, Satoshi S, Takifuji K, et al. Clinical features and management of hepatic portal venous gas: Four case reports and review of the literature. Arch Surg 2001; 136: 1410-4.

8. Lieman PR, Patten MT, Manny J, Benfield JR, Hechtman HB. Hepatic-portal venous gas in adult: etiology, pathophysiology and clinical significance. Ann Surg 1978; 187: 281-6.

9. Bloom RA, Lebensart PD, Levy P, Cracium E, Anner H, Manny J. Survival after ultrasonographic demonstration of portal venous gas due to mesenteric artery occlusion. Postgrad Med J 1990; 66: 137-9.

10. Friedman D, Flancbaum L, Ritter E, Trooskin SZ. Hepatic portal venous gas identified by computed tomography in a patient with blunt abdominal trauma: a case report. J Trauma 1991; 31: 290-2. 